\title{
What is the responsibility of Australian medical professionals whose patients travel abroad for assisted reproduction?
}

$25 / 10 / 18$

Jenni Millbank

\begin{abstract}
Australian medical professionals whose patients undertake assisted reproductive treatment abroad face a conflict: to try to provide optimal and on-going care for their patient at the same time as ensuring compliance with Australian legal, ethical and professional rules which proscribe as unsafe or unethical key aspects of such treatment.
\end{abstract}

A major suggestion from literature on medical travel is that risks to the patient can be mitigated through the involvement of the local professional. However, the force of legal regulation in Australia strenuously directs clinicians away from involvement in overseas reproductive treatment.

This article reports on 37 interviews with Australians travelling abroad for surrogacy, egg donation and embryo donation, reflecting on patients' experiences with Australian medical professionals both before and after they travelled. Patient reports demonstrate a fragmented and bewildering medical landscape in Australia, in which the ability to access domestic care and expertise varied markedly depending upon the kind of treatment patients were seeking abroad, and the mode of practice of the Australian doctor. Doctors practicing within licensed IVF clinics were notably more constrained than those outside such a setting. Patients seeking egg donation were offered information and received a wide range of diagnostic and preparatory treatments, while those seeking surrogacy were shunned, chided and offered limited (and sometimes covert) assistance.

While recent changes to National Ethical Guidelines improve clarity on information giving, the ethical and legal propriety of Australian medical professionals providing diagnostic or preparatory treatment for cross border reproduction remains uncertain.

\section{Keywords}

cross border reproduction; collaborative care; egg donation; professional responsibility; surrogacy; ethical guidelines

\footnotetext{
- Distinguished Professor of Law, UTS. This research project was conducted with Isabel Karpin and Anita Stuhmcke, funded through ARC DP 1510157, and undertaken with UTS Ethics Approval 2015000094. My deep thanks to Isabel, Anita and the journal reviewers for their comments on earlier versions of this article, to Norman O'Dowd, Rachel Carr and Michaela Stockey-Bridge for research assistance on the project, and to all of the interview participants for sharing their experiences and thoughts.
} 


\section{Introduction}

Commentators have expressed a range of concerns about the risks posed by medical travel. ${ }^{1}$ Feminist critics of cross border assisted reproduction practices have focused on the impact of inequality on the safety and informed consent of reproductive contributors such as surrogates and egg donors in destination countries, as well as the systemic entrenchment of inequalities in destination healthcare systems. ${ }^{2}$ Within broader medical travel, such as that for cosmetic, dental or bariatric surgery, analysts have tended to focus instead on risks to the travelling patient; through for example, incomplete or incompetent care abroad, or lack of follow up and poor record management or information flow between treating clinicians once home, ${ }^{3}$ and the resulting strain on local health systems when patients return with complications that require intensive care or extensive remediation. ${ }^{4}$

Heightened risks faced by Australians travelling abroad for assisted reproduction include ovarian hyperstimulation due to less stringent medication or monitoring protocols, multiple birth as a result of more common (and higher order) multiple embryo transfer, and, due to the lack of counselling and prevalence of donor anonymity in overseas treatment, possible later difficulties with disclosure and adjustment concerning donor conception if the donor's identifying information is desired by parents or offspring and cannot be accessed. ${ }^{5}$ This article

\footnotetext{
${ }^{1}$ Leigh Turner, 'Transnational Medical Travel: Ethical Dimensions of Global Healthcare' (2013) 22(2) Cambridge Quarterly of Healthcare Ethics 170.
}

2 Andrea Whittaker, 'Cross-Border Assisted Reproduction Care in Asia: Implications for Access, Equity and Regulations' (2011) 19(37) Reproductive Health Matters 107; Marcia Inhorn and Pasquale Patrizio, 'The Global Landscape of Cross-Border Reproductive Care: Twenty Key Findings for the New Millennium' (2012) 24(3) Current Opinion in Obstetrics and Gynecology 158.

\footnotetext{
${ }^{3}$ Turner, above $n$ 1; Leigh Turner, 'Quality in Health Care and Globalization of Health Services: Accreditation and Regulatory Oversight of Medical Tourism Companies' (2011) 23(1) International Journal for Quality in Health Care 1; Valorie Crooks et al, 'Ethical and Legal Implications of the Risks of Medical Tourism for Patients: A Qualitative Study of Canadian Health and Safety Representatives' Perspectives' (2013) 3(2) BMJ Open e002302.

4 Johanna Hanefeld et al, 'Medical Tourism: A Cost or Benefit to the NHS?' (2013) 8(10) PLOS ONE e70406; Turner, above $\mathrm{n} 1$.

${ }^{5}$ Jenni Millbank, 'Responsive Regulation of Cross Border Assisted Reproduction' (2015) 22 Journal of Law and Medicine 346. Such outcomes are of course also possible in IVF treatment within domestic systems such as those in Australia, but are posited as less likely due to legislation, policy and ethical guidance which aims to prevent them, discussed below.
} 
examines the conflict which lies in the competing obligations for Australian medical professionals whose patients undertake assisted reproductive treatment abroad: to try to provide optimal and on-going care for their patient at the same time as ensuring compliance with Australian legal, ethical and professional rules which proscribe as unsafe or unethical key aspects of such treatment.

A prominent suggestion from the general literature on medical travel is that risks to the patient can be mitigated through the involvement of the local professional both in assisting the patient with informed decision-making, ${ }^{6}$ and through collaborative care or continuity of care between the patient's home medical professionals and the treating professionals abroad. ${ }^{7}$ Such local involvement is said to lessen the likelihood of harm by ensuring that patients understand risks before making travel or treatment decisions, including an awareness of variations in ethical or clinical standards between their home and treating country, by reducing the need for lengthy or repeated travel through preparatory treatment at home, and mitigating risks of medical complications through record sharing and other forms of enhanced communication between professionals. ${ }^{8}$ Van Hoof et al go so far as to argue that such benefits may outweigh a medical professional's obligation to conflicting law in their own jurisdiction:

A local physician who is helping a patient evade the law may have a justifiable claim that there is no moral wrong in this act... The duty of care for the patient can outweigh the duty to uphold the spirit and essence of the law. ${ }^{9}$

\footnotetext{
${ }^{6}$ Jeremy Snyder et al, "'Do Your Homework... and Then Hope for the Best": The Challenges That Medical Tourism Poses to Canadian Family Physicians' Support of Patients' Informed Decision-Making' (2013) 14 (September) BMC Medical Ethics 37.

7 Turner, above n 3; Frances Shenfield et al, 'ESHRE's Good Practice Guide for Cross-Border Reproductive Care for Centers and Practitioners' (2011) 26(7) Human Reproduction 1625; Frances Shenfield et al, 'Cross Border Reproductive Care in Six European Countries' (2010) 25(6) Human Reproduction 1361.

${ }^{8}$ Shenfield at al 2010, above n 7, 1626; Edward Hughes and Deirdre DeJean, 'Cross-Border Fertility Services in North America: A Survey of Canadian and American Providers' (2010) 94(1) Fertility and Sterility e16; Wannes Van Hoof, Guido Pennings and Petra De Sutter, 'Cross-border Reproductive Care for Law Evasion: Should Physicians Be Allowed to Help Infertility Patients Evade the Law of Their Own Country?' (2016) 202 (July) European Journal of Obstetrics, Gynecology, and Reproductive Biology 101, 102-103.

${ }^{9}$ Van Hoof et al, above n 8, 105.
} 
In 2016 the Australian and New Zealand Royal College of Obstetricians and Gynaecologists (RANZCOG) issued a position statement on cross border reproductive care (CBRC). The statement recommends that individuals seeking CBRC 'should have an informed discussion' with a specialist in obstetrics and gynaecology, taking into account suitability for pregnancy and the welfare of the unborn child, before travelling, and also that patients who have undertaken CBRC should not be subject to penalties or restrictions on care upon their return. The statement also recommends that:

Practitioners facilitating CBRC should be familiar with their local regulatory and legal obligations. Practitioners are at all times subject to local regulations... Medical practitioners should be aware that significant penalties may apply for facilitation of certain reproductive practices, such as commercial surrogacy. ${ }^{10}$

The RANZCOG guidance is patient-centred in that it encourages informed decision-making before the decision to travel and continued care after travel. However, it provides no assistance on the knotty question of what degree of involvement a practitioner may ethically have in terms of diagnosis and preparatory treatment or engagement in a process of collaborative cross-border care. ${ }^{11}$

The injunction to practitioners to 'be familiar' with regulatory and legal obligations is easier said than done. The force of legal regulation and ethical guidance in Australia strenuously directs clinicians away from any involvement in overseas reproductive treatment. Yet it does so with varying strictures as between different practices (egg donation versus surrogacy), and as between different practitioners and sites of practice (fertility specialists working within licensed IVF clinics versus specialists operating outside of clinics and general practitioners (GPs)). Notably, what constitutes prohibited 'facilitation' practices has never been defined.

\footnotetext{
${ }^{10}$ Royal Australian and New Zealand College of Obstetricians and Gynaecologists, Cross-border Reproductive Care (2016), $\quad 3 \quad<$ https://www.ranzcog.edu.au/RANZCOG_SITE/media/RANZCOGMEDIA/Women\%27s\%20Health/Statement\%20and\%20guidelines/Clinical\%20-\%20Gynaecology/Cross-BorderReproductive-Care-(C-Gyn-36)-New-March-2016.pdf?ext=.pdf> accessed 25 October 2018.

${ }^{11}$ Likewise see the US professional association guidelines on CBRC, which assumes throughout that the home physician is not the treating physician: Ethics Committee of the American Society for Reproductive Medicine (ASRM), 'Cross-Border Reproductive Care: An Ethics Committee Opinion' (2016) 106(7) Fertility and Sterility $1627,1631$.
} 
In 2017 the Australian National Ethical Guidelines on assisted reproductive technology tackled CBRC in some detail for the first time in their 35-year history. ${ }^{12}$ While these revisions provide greater clarity on information giving, and greater consistency on approaches between egg donation and surrogacy, they continue to direct practitioners away from continuity of care. Moreover, the National Ethical Guidelines continue to be situated within a patchwork framework of regulation: applying only to clinicians operating within licensed IVF clinics, such that they may continue to be sidestepped by other medical practitioners. This article argues that a fragmented and inchoate approach to ethical duties in Australia has fuelled a series of elaborate 'grey zones' which both patients and practitioners have occupied and expanded as the Australian uptake of CBRC has continued to grow.

The context for this discussion is provided by empirical findings drawn from interviews with Australians travelling abroad for assisted reproduction, reporting on patients' actual experiences with Australian medical professionals both before and after they travelled. The views and experiences of interviewees are drawn upon to situate this ethical discussion within a pragmatic lived context, in which patients experienced themselves as 'helped', 'supported', or 'turned out in the cold', and professionals as nudging them in particular directions or 'selling them into' services, within a confusing maze of Australian and destination country regulation.

Little is known about the extent to which local medical professionals participate in CBRC. ${ }^{13}$ In 2010 the European Society of Human Reproduction and Embryology (ESHRE) published a survey of 1,230 foreign patients at forty-six IVF clinics in six destination countries. Among respondents 59 per cent reported that they had received some help from their own doctor, for drug prescription (16.7\%), cycle monitoring (16.7\%) or both $(25.6 \%) .{ }^{14}$ However, the level of involvement varied widely depending upon the patient's home country: there was a high

\footnotetext{
12 National Health and Medical Research Council, Ethical Guidelines on the Use of Assisted Reproductive Technology in Clinical Practice and Research (2017) https://www.nhmrc.gov.au/guidelines-publications/e79 accessed 5 October 2018.

${ }^{13}$ Marcia Inhorn and Zeynep Gürtin, 'Cross-Border Reproductive Care: A Future Research Agenda' (2011) 23(5) Reproductive BioMedicine Online 665 .

${ }^{14}$ Shenfield at al, 'Cross Border Reproductive Care in Six European Countries', above n 7, 1364.
} 
level of medical support in Germany (81.7\%), compared to the UK which was one of the lowest at $45.3 \%$ (of 53 UK patients). ${ }^{15}$ In Culley et al's 2011 qualitative study of 51 British patients who undertook CBRC, 18 participants reported no involvement or assistance from UK healthcare professionals. Another 18 participants reported some assistance, mostly for preparatory ultrasounds or prescriptions, on an ad hoc basis; only six among them reported assistance from their home fertility clinic. ${ }^{16}$ Culley notes, 'Many of our participants reported that they would have appreciated recommendations on overseas clinics from UK clinics, and assistance with preparation and follow up'. ${ }^{17}$

The findings in the present study of Australian patients is broadly consistent with the international data cited above. Twenty-two of 37 participants who undertook treatment abroad (59\%) reported some involvement from Australian health practitioners in their CBRC process; but only a minority reported on-going involvement from a treating fertility doctor. This low level of specialist involvement is arguably a consequence of the Australian system of fertility regulation, explained below.

\section{The study}

The broader study examined the experiences of Australians who travel, both internationally and within Australia, to undertake assisted reproduction. Semi-structured interviews took place between June 2015 and June 2018 with a total of 93 interviews conducted. ${ }^{18}$ The total

\footnotetext{
15 Ibid.

${ }^{16}$ Lorraine Culley et al, 'Crossing Borders for Fertility Treatment: Motivations, Destinations and Outcomes of UK Fertility Travellers' (2011) 26(9) Human Reproduction 2373, 2376.

${ }^{17}$ Ibid.

18 Interviews were transcribed, anonymised, and entered into NVivo software to enable thematic coding and analysis. All three investigators contributed to coding themes and held multiple meetings to discuss and crosscheck coding in order to ensure consistency of approach.
} 
cohort comprised 66 interviews with patients ${ }^{19}$ and 27 with a variety of professionals. ${ }^{20}$ All participants are referred to with pseudonyms.

Among the patient group were 37 interviews with people who had travelled overseas. Countries travelled to were: India, Thailand, Nepal, Mexico, Spain, South Africa, Greece, Canada, and the USA. ${ }^{21}$ Ten participants had travelled to more than one country in different attempts. Several participants also undertook treatment with more than one provider in a given country in subsequent pregnancy attempts. Twenty interviews involved participants who had undertaken one or more surrogacy arrangements overseas (seven gay men, 12 women in heterosexual relationships and one man and woman interviewed as a couple). Seventeen interviewees were of patients who travelled to undertake egg or embryo donation in order to try to achieve a pregnancy themselves (16 women and one man and woman interviewed as a couple). ${ }^{22}$ Among a number of other topics, patients were asked about their engagement with Australian health professionals in their process. The interviews revealed significantly more local health practitioner involvement in cross border reproductive treatment than the researchers had anticipated. While it is not possible to know whether this is representative of the experiences of Australian fertility travellers more broadly, this qualitative interview data provides valuable insights into patient's experiences and perceptions of local care in CBRC.

\footnotetext{
${ }^{19}$ This figure does not include five follow-up interviews with patients who had been very early in their CBRC arrangements at the time of the original interview.

${ }^{20}$ These professionals included: doctors, regulators, lawyers, counsellors, agents and facilitators. Among the professionals were three Australians who had also previously travelled overseas as intended parents to undertake surrogacy. For analysis of the professionals see Jenni Millbank, 'The Role of Professional Facilitators in Cross Border Assisted Reproduction' (2018) Reproductive BioMedicine \& Society Online, forthcoming.

${ }^{21}$ At the time of interview, participant's average age was 42 . While interviewees had travelled for treatment between 11 years and six months previously, the average (and median) time since travel was two years.

${ }^{22}$ Among interviewees, 30 had children born as a result of CBRC and a further four participants were pregnant at the time of interview. Apart from multiple births, most parents had only one child through CBRC. Five participants had a subsequent child or pregnancy through further overseas treatment at the time of interview, and a further four parents through overseas surrogacy were still pursuing a subsequent surrogacy arrangement at the time of interview. Three other interviewees who had undertaken CBRC without success later had children through other means: one through domestic surrogacy and two through domestic adoption/permanent placement.
} 
Who is travelling, for what, and how this is at odds with Australian standards

Surrogacy and egg donation are lawful throughout Australia, with relatively liberal access and a broad range of private providers of assisted reproductive treatments. Yet Australians are notable consumers of CBRC in a wide variety of destination countries.

Current evidence suggests that Australian women travel abroad to undertake egg donation to access donor eggs more quickly, and with a wider range of choice, than they would be able to within Australia. ${ }^{23}$ Egg donor agencies in destination countries recruit young women (typically under 25 years old) and pay them, or arrange for them to be paid, a set sum. ${ }^{24}$ Although payments vary widely across jurisdictions (from around $\$ 800$ AUD in South Africa to $\$ 5000$ and upwards in the USA) such a fixed sum is not a direct reimbursement of out-ofpocket expenses and so would be regarded as 'valuable consideration' or commercial trading under Australian law. ${ }^{25}$ Common destinations for Australians seeking egg donation at the time of writing are South Africa, Greece, Spain and the USA, and this was reflected in the cohort of the present study. ${ }^{26}$

The anonymity of egg donors in mandated by law in South Africa, Spain and Greece. In the USA the use of unidentifiable donors remains common practice, but some services also offer identifiable donors (across a range such as 'open' donors whose identity is available at the time, or 'identity release' donors who consent to be identifiable at a later point). Among all

\footnotetext{
${ }^{23}$ Iolanda Rodino, Sonja Goedeke and Sarah Nowoweiski, 'Motivations and Experiences of Patients Seeking Cross-Border Reproductive Care: The Australian and New Zealand Context' (2014) 102(5) Fertility and Sterility 1422, 1425 ; Author ref; and see similar findings on UK travellers Culley et al, 'Crossing Borders for Fertility Treatment', above n 16.

${ }^{24}$ Guido Pennings et al, 'Socio-Demographic and Fertility-Related Characteristics and Motivations of Oocyte Donors in Eleven European Countries' (2014) 29(5) Human Reproduction 1076.

${ }^{25}$ See eg Prohibition of Human Cloning for Reproduction Act 2002 (Cth) s 21; Human Reproductive Technology Act 1991 (WA) s53Q.

${ }^{26}$ See also findings from this research that those destinations, and the Czech Republic, were a focal point of Australian women's discussions in a major on-line peer discussion forum: Stuhmcke et al, forthcoming.
} 
interviewees who undertook egg and embryo donation overseas, only four, all of whom undertook treatment in the USA, had an identifiable donor - and all reported that this arose out of their own insistence on this requirement. While many commentators assume that those travelling to jurisdictions with donor anonymity do so because they are actively seeking anonymous donors, ${ }^{27}$ this and other Australian studies do not bear out that assumption. ${ }^{28}$ In fact only four egg recipients, Olivia and Madeline (USA), Shelby (Greece) and Katinka (South Africa) indicated that an unidentifiable donor was their preference. The majority of interviewees simply stated that this was 'how things were' and accepted it as their 'only chance'. Indeed, five interviewees had connected with other sibling and half-sibling families through voluntary registers and other means, even without identifying information on the donor/s.

Since the late 1990s, Australia has strongly promoted single embryo transfer in order to reduce multiple births associated with IVF, which are now among the world's lowest, at $4.4 \%$ of IVF births for $2015 .{ }^{29}$ This is not so in many destination countries, where double embryo transfer remains the norm in IVF generally, with an even higher incidence of multiple embryo transfer in surrogacy. A recent large scale retrospective analysis of USA fertility clinic data from 2006-2013 found an average of two embryos transferred per donor IVF cycle, with a resulting multiple birth rate of $20.8 \% .^{30}$ Women in the present study undertaking egg donation abroad in order to achieve their own pregnancy reported between one and three

\footnotetext{
27 See eg Ethics Committee of the American Society for Reproductive Medicine, 'Cross-Border Reproductive Care: a Committee Opinion' (2010) 100 Fertility and Sterility 645.
}

\begin{abstract}
28 Note that in the survey study by Rodino et al, a desire to use an anonymous donor was the least common motivation for travel at 16\%: above $n 23,1425$. This is on par with international data: Shenfield et al above $n 7$ reported that overall $17.9 \%$ of respondent patients indicated a wish for anonymous donation as a reason for travel: at 1363; Culley et al above n 16 at found that only $10 \%$ of their 51 participants expressed this desire: 2379.
\end{abstract}

${ }^{29}$ Oisin Fitzgerald et al, Assisted Reproductive Technology in Australia and New Zealand 2015 (2017), 50; dual embryo transfer still occurred in 14\% of treatment cycles in 2015 but notably dual embryo transfer is lower among egg and embryo recipients than women undertaking autologous cycles: ibid, 54 and Supplementary Report, Table S4, 4.

\footnotetext{
${ }^{30}$ Aaron Levine et al, 'Assessing the Use of Assisted Reproductive Technology in the United States by Non-United States Residents' (2017) 108(5) Fertility and Sterility 815, 818, although notably this was the same for both local and overseas patients.
} 
embryos per transfer, with two embryos reported as the expected 'norm' in all four destination countries. ${ }^{31}$ As with anonymity of donors, interviewees did not generally report that they travelled seeking this practice; rather it was just 'how things were done' in the destination country.

All except one of the 17 women undertaking egg or embryo donation abroad had undertaken extensive IVF treatment within Australia utilising their own eggs, and at least five women had also undertaken subsequent IVF within Australia using donated eggs. As a consequence, these women had received extensive advice on multiple embryo transfer and the risks involved in multiple pregnancies during prior treatment. This greater awareness meant that several women reported that they had refused double embryo transfer overseas on one or more treatment occasions. This may have had some impact upon the incidence of multiple births, although the rate was still considerably higher than in domestic treatment: of 11 births and four resulting pregnancies in the overseas egg donation group, there were three multiple pregnancies, all of which were twins. (Likewise of 32 resulting pregnancies in Culley et al's UK study, 6 or $19 \%$ were twins). ${ }^{32}$

Australian women and men who travel overseas to undertake surrogacy do so for a range of reasons which include: local legislative barriers to access in some states (such as the exclusion of gay men from regulated surrogacy in Western Australia), perceptions of unavailability or complexity of domestic surrogacy, the desire to access professional intermediation and matching services, the desire for (the appearance of) legal certainty around parentage and surrogacy obligations, and the belief that overseas providers are more successful and accessible. ${ }^{33}$ When gay men undertake surrogacy, or when a female intended parent is unable to contribute her own eggs, overseas surrogacy arrangements also include the use of egg donation services such as those described above. Within the 20 interviews of those who

\footnotetext{
${ }^{31}$ And see Culley et al on comparable UK experience, 'Crossing Borders for Fertility Treatment', above n 16, 2377.

32 Ibid.

${ }^{33}$ Sam Everingham, Martyn Stafford-Bell and Karin Hammarberg, 'Australians' Use of Surrogacy' (2014) 201(5) The Medical Journal of Australia 270; Rodino et al, above n 23, 1425, 1426; Emily Jackson et al, 'Learning from Cross-Border Reproduction' (2017) 25(1) Medical Law Review 23.
} 
undertook surrogacy abroad, 16 had also utilised donor eggs in one or more surrogacy attempts.

Common destinations for Australians in the 2000s seeking surrogacy were India and Thailand. Following regulatory crack-downs, operators migrated across to Nepal and Cambodia, respectively, as well as Mexico, before these jurisdictions, too, were shut down. ${ }^{34}$ Canada, the USA, Ukraine and Kenya are surrogacy destinations at the time of writing.

Surrogacy agencies recruit and match surrogates with intended parents and oversee the execution of contractual arrangements which purport to be directly between the surrogate and parents. Such contracts typically involve a series of instalments of set payments to surrogates in addition to actual expenses, totalling around $\$ 8000$ in India or Thailand (in the past) to $\$ 30,000-\$ 50,000$ in the USA. As with egg donation, payments to surrogates above directly incurred reasonable expenses are unlawful in Australia. ${ }^{35}$

In contrast to egg donors, surrogates are identifiable in most current destination countries (although notably in India surrogates were more likely to be secreted from both social networks and intended parents, with deleterious effects on their well-being). ${ }^{36}$ In the USA and Canada it is common practice for intended parents and surrogates to meet and to maintain a relationship during the pregnancy, and often afterwards. As with egg recipients, only a minority of intended parents undertaking surrogacy utilised identifiable egg donors; reflecting the fact that most destination jurisdictions for surrogacy also mandated gamete donor anonymity. As with the egg donation cohort, the use of identifiable donors in surrogacy resulted from the intended parents' own strong preference and occurred mostly in the USA, but also in two arrangements in Thailand and one in India (in which the intended parent met the Ukrainian egg donor by chance at the clinic and established a friendship).

\footnotetext{
34 Jackson et al, above n 33, 24; Everingham et al, above n 33.

35 Through state and territory law, see eg Assisted Reproductive Treatment Act 2008 (Vic) s 44.

${ }^{36}$ Nitin Lamba et al, 'The Psychological Well-Being and Prenatal Bonding of Gestational Surrogates' (2018) 33(4) Human Reproduction 646.
} 
Multiple embryo transfer has been reported as common practice in international surrogacy; up to four embryos was common in the past in India, with two to three still accepted in the USA (resulting in a multiple birth rate of over 42 per cent among gestational surrogates there). ${ }^{37}$ In a 2014 survey of 112 Australians who had travelled overseas for surrogacy, the mean number of embryos transferred was 2.9 and 62 participants (55\%) reported that their surrogacy involved a multiple pregnancy (with a resulting $45 \%$ of births premature). ${ }^{38}$ The experience of interviewees in the present study was comparable with these findings, with participants reporting between one and four embryos transferred per surrogacy attempt, and two as 'the norm'. Of the 18 interviewees reporting births from overseas surrogacy arrangements, eight were multiple births; seven twins and one set of triplets. As with the egg donation cohort, an insistence upon single embryo transfer arose in the surrogacy interviewees among some women who had undertaken previous IVF in Australia, but this appeared to be less common.

\section{The Australian legal and ethical landscape}

Australian regulation places a strong emphasis on altruism across all elements of reproductive contribution. The 2017 National Ethical Guidelines state that:

The current situation in Australia is that gamete donation must be altruistic, and that commercial trading in human gametes or the use of direct or indirect inducements is prohibited by legislation. This position reflects concerns about the potential exploitation of donors (particularly egg donors) and the potential risks to all parties. ${ }^{39}$

and

Commercial surrogacy, where the surrogate receives financial compensation above and beyond expenses associated with the surrogacy procedure and pregnancy, is ethically unacceptable because it raises concerns about the commodification and

\footnotetext{
${ }^{37}$ Kiran Perkins et al, 'Trends and Outcomes of Gestational Surrogacy in the United States' (2016) 106(2) Fertility and Sterility 435.

38 Martyn Stafford-Bell, Sam Everingham and Karin Hammarberg, 'Outcomes of Surrogacy Undertaken by Australians Overseas’ (2014) 201(6) Medical Journal of Australia 330, 331.

${ }^{39}$ National Health and Medical Research Council, above n 12, [5.4].
} 
exploitation of the surrogate, the commissioning parent(s) and any person born as a result of the surrogacy arrangement. ${ }^{40}$

There is no ethical distinction drawn between payment for surrogacy or for egg donation in these guidelines. Likewise, legislative objectives are expressed in very similar terms when proscribing payment for gametes, embryos and surrogacy. Yet, the way in which prohibitions on payment have been enacted in legislation and publicised are widely divergent, and have arguably resulted in a situation in which payment for surrogacy is perceived as somehow really illegal while payment for eggs is overlooked entirely or viewed as a merely technical breach.

Trading in gametes is a criminal offence under Australian federal and state law if undertaken within Australia; this includes the giving, receiving, or offering to give or receive, valuable consideration, such that offences would encompass the actions of the egg donor, the agent or agency and the egg recipient in most forms of overseas arrangements if taking place within Australian jurisdiction. ${ }^{41}$ Very little attention has been paid to the fact that some, perhaps most, Australians entering into paid arrangements with egg donors abroad through online mediums are actually within Australian borders at the time they offer the payment, and possibly also while they transfer the payment. Even though the egg is being provided overseas, there is the real possibility that some patients are still committing one or more criminal offences before they travel.

All Australian states currently criminalise commercial surrogacy if it is undertaken within the relevant state, through prohibiting the giving or offering of payment, receiving or offering to receive payment, as well as prohibiting intermediaries and often prohibiting advertising. ${ }^{42} \mathrm{As}$

\footnotetext{
40 Ibid 65.

${ }^{41}$ While penalties for individuals previously ranged from fines alone under state and territory law (see eg Transplantation and Anatomy Act 1978 (ACT) s 44, a \$7000 fine) to a maximum of 6 months imprisonment and/or a \$4440 fine (eg Human Tissue Act 1983 (NSW) s 32) - this was increased to a markedly more onerous 15 years imprisonment under federal law in 2002, and then mirrored through into state laws subsequently, as a result of attempts to prevent human cloning and the use of donated gametes in unlicensed research: see Prohibition of Human Cloning Act 2002 (Cth) s 21; Prohibition on Human Cloning Act 2008 (Vic) s 17.

${ }^{42}$ Anita Stuhmcke, 'The Criminal Act of Commercial Surrogacy in Australia: A Call for Review' (2011) 18(3) Journal of Law and Medicine 601; Anita Stuhmcke, 'The Regulation of Commercial Surrogacy: The Wrong Answers to the Wrong Questions' (2015) 23(2) Journal of Law and Medicine 333; Angela Campbell, Sister Wives, Surrogates and
} 
with offering payment for eggs, it is often overlooked that those who offer payment for surrogacy (and who act as intermediaries for paid surrogacy) could actually be committing offences as they sit at their keyboards in Australia sending emails or Facebook messages, even though the execution of the actual arrangement and payment may ultimately take place offshore.

Commonality in the ethical basis, and fundamentals of the legal prohibitions, concerning payments for eggs and for surrogacy has been overshadowed by the unusual extraterritorial criminal offences concerning commercial surrogacy in three jurisdictions; the ACT, Queensland and NSW. These provisions explicitly extend criminal liability to those who are ordinarily resident in those jurisdictions even if the entirety of their conduct takes place elsewhere. ${ }^{43}$ This means that even if every aspect of a commercial surrogacy arrangement, offer and all, take place abroad, residents from those three jurisdictions are still caught by such criminal prohibitions. These provisions received significant media attention and adverse commentary, particularly in NSW, as in 2010 NSW was the only jurisdiction to actually introduce this provision (rather than simply carrying it over from earlier laws) as part of what was an otherwise 'liberalising' wave of surrogacy reforms throughout Australia.

Licensed IVF clinics are subject to an additional form of regulation in that they must comply with National Ethical Guidelines. ${ }^{44}$ These Guidelines are consulted upon and reissued every 10 years or so, and they reflect developing understandings, evidence and norms concerning both safety and ethical standards in assisted reproduction. Since 2007, compliance with these

Sex Workers: Outlaws by Choice? (Ashgate, 2013). Penalties for individuals engaged in commercial surrogacy range across the states from one to three years' imprisonment and/or fines of between $\$ 4,000$ to $\$ 110,000$.

43 Stuhmcke 2015 above n 42; Jenni Millbank, 'Rethinking “Commercial” Surrogacy' (2015) 12 Journal of Bioethical Inquiry 477.

44 In three Australian states there is also stand-alone legislative regulation of assisted reproductive treatment. For the purposes of this discussion it is important to note that they add to the confusion outlined above for professionals involved in fertility treatment because they contain additional obligations, addressing issues such as supply or export from the jurisdiction, and these vary depending upon whether the object of regulation-the gamete or embryo-is defined as formed from donor gametes or not: see eg Assisted Reproductive Treatment Act 2008 (Vic) s 36. See eg a number of recent cases concerned with whether deceased men's sperm is 'donated' when their surviving partner wishes to remove it from the jurisdiction for her own use: Chapman v South Eastern Sydney Local Health District [2018] NSWSC 1231; GLS v Russell-Weisz [2018] WASC 79. 
Guidelines has been a federal statutory condition of licence for IVF clinics. ${ }^{45}$ All but one of our patient cohort were reporting upon treatment undertaken under the 2004/2007 Guidelines, so these will be addressed first before turning to the new challenges posed by the 2017 Guidelines at the conclusion of this article.

Within Australia, single embryo transfer is mandatory in surrogacy, and very strongly encouraged in all other IVF cycles. ${ }^{46}$ Since 2004, the National Ethical Guidelines have asserted emphatically that it is the right of donor conceived people to be able to access information on their genetic heritage, prohibited Australian IVF clinics from undertaking gamete donation with anonymous donors, and included numerous provisions for the mandatory storage and release of identifying information on donors (which had at that time had only been provided for by law in two states). ${ }^{47}$

The $2004 / 2007$ Guidelines appeared to craft a broader scope of responsibility for professional actions concerning surrogacy compared to egg donation. Under the heading 'Do not trade in human gametes', the Guidelines provided, 'Commercial trading in human gametes and/or the use of direct or indirect inducements, must not be undertaken', ${ }^{48}$ thus addressing direct engagement in the practice of payment for gametes. This was comparable to the requirements concerning single embryo transfer and donor identification in that the obligation concerned the treatment which the clinician or clinic was directly providing. In contrast the wording concerning surrogacy was both broader and less clear. Under the heading, 'Do not undertake or facilitate commercial surrogacy', the Guidelines repeated the phrase 'undertake or facilitate' concerning the prohibition of involvement in pregnancies and

\footnotetext{
${ }^{45}$ Research Involving Human Embryos Act 2002 (Cth) ss 10, 11.

${ }^{46}$ Reproductive Technology Accreditation Committee, Code of Practice for Assisted Reproductive Technology Units (2017) [3.3] <https://www.fertilitysociety.com.au/wp-content/uploads/2017-RTAC-ANZ-COP-FINAL1.pdf> accessed 25 October 2018; also similarly 2015, 2010.

47 See discussion in Jenni Millbank, 'Identity Disclosure and Information Sharing in Donor Conception Regimes: The Unfulfilled Potential of Voluntary Registers' (2014) 28 International Journal of Law, Policy and Family 223; see Guidelines above $\mathrm{n} 12$ and below $\mathrm{n} 48$.

${ }^{48}$ National Health and Medical Research Council, Guidelines on the Use of Assisted Reproductive Technology in Clinical Practice and Research (2007) [6.5] <https://www.nhmrc.gov.au/guidelines-publications/e78>.
} 
in arrangements. ${ }^{49}$ The $2004 / 2007$ commercial surrogacy prohibition was thus understood by many to include the provision of diagnostic medical care, as well as referral or information and advice to a patient who was involved in or planning a paid surrogacy arrangement abroad. ${ }^{50}$ As will be discussed below the undefined prohibition on 'facilitation' appears to have had a major impact upon the differential treatment of patients pursuing surrogacy as opposed to egg donation.

The more intense regulation of doctors within IVF clinics compared to other medical professions, and vaguer prohibitions on the conduct of those working within IVF clinics concerning surrogacy compared to egg donation, correlated strongly-but not completelywith patients' experiences of their health professionals in the present study. Interviewees reported far more assistance from GPs than fertility specialists for surrogacy, and much more extensive involvement from both groups when it came to egg donation.

How Australian health professionals are engaging with patients undertaking international egg donation and surrogacy

Participants reported the involvement of Australian health professionals across a range of areas, through:

- referrals and information giving;

- diagnostic work;

- preparatory treatment; and

- follow up treatment.

\section{Referral and information giving}

Within this study direct referral from an Australian health or medical practitioner to a particular overseas provider was rare. There were no reported referrals concerning surrogacy, and only three participants reported that their fertility doctor specifically referred them to an overseas provider for egg donation.

\footnotetext{
${ }^{49}$ Ibid [13.1].

50 See Millbank above $\mathrm{n} 5$.
} 
Among the three egg donation referrals, experiences were varied. Katinka did not follow the referral, preferring to seek out peer information sources. Shelby found her referral to be a negative experience because she felt that her local doctor was not giving her impartial advice about his 'mate' in Greece. Shelby undertook one round of treatment which she described as chaotic, with poor communication from the recommended clinic:

The experience of that week in Greece was pretty awful. We paid the fertility specialist here ... to manage the process, discovered what that meant was he sent them an email telling them I'd be coming and his secretary gave me a photocopy of my file... The [Greek clinic] was like a zoo and we waited five hours for an appointment and when we did get to see him ... He hadn't read anything. He didn't have the file already.

The communication was really bad. The information about the drugs that I had to take was really bad... they told me verbally [a] different dosing regime [to the one] in writing and gave me something different. I kept trying to contact them ... about which doses I should be taking and never got return calls. I ended up contacting my specialist back here in Australia who said, "Just take the doses that I told you. Don't worry about the fact that you're not getting contact from them. That's just the way it works. It'll all be fine."

As a consequence, Shelby left her fertility specialist in Australia and ceased using the clinic in Greece (although she was very positive about a second clinic she subsequently went to in Greece as result of peer recommendations through the internet). In contrast, Millie was very happy that the South African doctor she was referred to had a long-standing professional relationship with her local fertility doctor. Millie experienced this as a collaboration in which there was trust on both sides and improved communication and continuity of care as a result.

She knows him very well professionally, so we had that continuity of care so [my IVF doctor] would talk to him and he could talk to [her] directly... they could share information. She knew that I would be well cared for in South Africa. Conversely [the South African] doctor knew that I would be well cared for in Australia when I got back, so there was absolutely no issues with me going.

General information-giving concerning overseas egg donation was commonly reported as volunteered by, rather than solicited from, fertility professionals. Multiple participants noted that in the process of undertaking IVF in Australia, their fertility doctors, nurses, and embryologists 'suggested' or mentioned egg donation overseas as their 'best option'. This was general information rather than a specific referral as the following quotes make clear.

[My fertility doctor] straight up [said] that you can go to various clinics overseas, because the waiting lists are very, very long. You basically never get to the end of it.... She suggested to me three countries at that stage. (Leah, egg donation, Greece) 
Actually an IVF doctor said to me, I think you should look at other countries... he said I think you need to look abroad. South Africa is an option. (Amanda, egg donation, South Africa)

[My IVF doctor] said to us that our best chance was to do it overseas because the quantity of available, and quality [of Australian] donors was not very high. .... So he let me know the four countries that had the best progress and then basically said go and do the research. So he said the US, Greece, South Africa and Spain. (Cassandra, egg donation, Greece)

Notably, no participant reported a negative response from their fertility doctor or other health professional concerning overseas egg donation. Some, such as Rosalind who undertook egg donation in Greece, said that her local fertility clinic nurses and counsellors were keen for knowledge about her treatment abroad as they saw it as 'another option' for their patients who were unsuccessful in Australia. When Zara, who had unsuccessfully undertaken egg donation with two separate known egg donors in Australia, both of whom were in their 30s, told her clinic staff that she was going to South Africa the embryologist wished her well 'and also said, "choose someone young".'

In contrast to egg donation, when patients initiated discussions about overseas surrogacy with fertility specialists they were generally met with responses which they described as hostile or discouraging. These findings align with the responses in a survey study by Hammarberg et al of 249 Australians who had undertaken or planned to pursue paid surrogacy overseas. They found that few sought information from a local general practitioner or IVF clinic and those who did reported that IVF clinic staff were significantly more likely than other groups to express negative reactions. ${ }^{51}$

Gerry, who ultimately undertook surrogacy in Canada, said that when he called Australian IVF clinics seeking information, 'they just wanted to terminate the conversation very quickly.' Jody, who undertook surrogacy in the USA, stated similarly of her Australian IVF clinic,

\footnotetext{
51 In that study, 26\% of participants reported a negative reaction from a doctor in their IVF clinic, and $29 \%$ reported a negative reaction from a clinic nurse or counsellor: Karin Hammarberg, Martyn Stafford-Bell and Sam Everingham, 'Intended Parents' Motivations and Information and Support Needs When Seeking Extraterritorial Compensated Surrogacy' (2015) 31(5) Reproductive BioMedicine Online 689, 693.
} 
as soon as you say the word surrogacy they just kind of shut you down. Even one of the nurses who I became quite friendly with, she said "do not say that word in our offices."

Dian, who was born without a uterus, characterised this as the 'door just shutting' when she tried to raise the topic with her fertility specialist. This meant that Dian travelled to India to attempt surrogacy with her own eggs without having had a thorough preliminary investigation into her fertility. After three weeks in India Dian's eggs were retrieved and found to be unusable, and her hormone levels indicated that any further attempt was very unlikely to succeed.

Cheryl also undertook surrogacy in India with own eggs and said:

[My doctor] ... was very against offshore surrogacy. I mentioned it to her just to get her idea and she said 'oh that's terrible. These are women that are terribly exploited and you'll go over there and you'll get a disease and you'll be in some terrible baby factory and what not'. Anyway, she said those things and then I just shut down that dialogue with her.

Notwithstanding this negative response and the subsequent breakdown of her therapeutic relationship with her fertility specialist, it is notable that Cheryl was the one intended parent undertaking surrogacy in India to insist upon single embryo transfer, based upon her own prior experience of IVF in Australia:

[E]very doctor here [in Australia] is so, so adamant that you should only transfer one. Twins are not - twins are something that you want to avoid if you can, if you have a choice about that. (Cheryl, surrogacy, India)

Hammarberg et al note that, "health professionals have a duty of care to people who seek their advice' and argue that doctors must be able to provide 'objective and comprehensive information about all aspects of surrogacy'. ${ }^{52}$ The example of Cheryl above demonstrates that even in a situation where a doctor believes the overseas treatment to be unsafe or unethical, their specialist knowledge and advice may still be instrumental in preventing or minimising harm to reproductive contributors, their patient and any subsequent child.

52 Ibid 694. 
Informed consent in overseas treatment requires a good understanding of both clinical and ethical (or psycho-social) dimensions of treatment abroad, and how this compares to local treatment. The experience of participants demonstrates limited involvement of Australian health professionals in information-giving practices about CBRC. Very few participants reported receiving specific advice from their local medical practitioner about risks commonly associated with overseas treatment, such as multiple embryo transfer or ovarian hyperstimulation. Jane and Alice (discussed below), both undertook surrogacy in India using their own eggs, and reported experiencing ovarian hyperstimulation. The incidence of ovarian hyperstimulation in overseas treatment cannot be known. This is because for most participants, ovarian hyperstimulation was a risk faced by their egg donor rather than themselves (as only the women undertaking surrogacy with their own eggs were themselves undertaking a stimulated cycle of egg retrieval). When participants utilising an egg donor were asked whether they had any concerns about clinical risks to the donor, they typically responded that it was 'very safe', because the clinic in the destination country had assured them that this was so. However, some also reported results which could be interpreted as indicating hyperstimulation, such as 40 eggs being retrieved in a single cycle. Tom, who undertook surrogacy in India with a Ukrainian egg donor, only discovered years later when seeking out his egg donor for another pregnancy attempt that she had been overstimulated and was dangerously unwell following her original treatment.

It was also apparent that most participants had not received targeted counselling or information about donor conception. Within Australian IVF treatment counselling is generally voluntary for those utilising their own gametes but mandatory if donor gametes are used or surrogacy is involved. As only a handful of participants had undertaken domestic treatment with donated gametes prior to travel, the great majority of participants had not undertaken 'implications counselling' about gamete donation (which generally includes information on disclosure to the child, how identifying information is stored and how and when it may be 
accessed) within Australia. ${ }^{53}$ No participant reported being offered such counselling as part of their overseas treatment. ${ }^{54}$

As noted above, while a small number of interviewees stated that they preferred or sought anonymity in a donor, most simply accepted the prevailing regime in the country of treatment and, arguably, had not been assisted or encouraged to consider the issue in any depth. Therese, who was pregnant at the time of interview, following four rounds of egg donation in Spain, said:

If the child wants to know, I can't help it, we made a decision and it was our decision, it is shitty for them if it's not what they think would be the right decision, but we actually didn't feel like we had many choices. I didn't want to pick the kid with the small tidy ears, I just wanted a baby.

Dina, who received both donor egg and donor sperm in treatment in Greece, and at the time of the interview had a seven year old son, would have preferred identity release donors as well as more information on the donors:

I didn't get any photos. That's the issue I've got now, that there was nothing identifying for my child, for my son, to be able to relate to.

Shelby had a three year old son from egg donation in Greece, and was pregnant with another child from the same donor at the time of interview. Although she stated that she preferred an anonymous donor, Shelby nonetheless expressed ambivalence about this outcome:

It would have been - it would be nice for Thomas to have the option to send something over there and say "you know what, l'd kind of like to get in touch with you" and if she's open to that then she could be contacted. That option doesn't exist in Greece. It's just - the anonymity is rock solid. There's no indication that that's going to change. Maybe it will in 20 years but certainly at the moment that's just not an option that Thomas is ever going to have. I'm sad for him that he doesn't have that because I'd like him to be able to choose if he wanted to...

53 On the legal and ethical requirements for counselling in Australia see Eloise Chandler et al, 'Rethinking Consent, Information Giving and Counselling Concerning Stored Embryos in IVF treatment' (2013) 20 Journal of Law and Medicine 759, and current Guidelines above $\mathrm{n} 12$ [4.2.3], [4.4.1]; on the content of such counselling see Australia and NZ Infertility Counsellors Association, Guidelines for Professional Standards of Practice (2003) at https://www.fertilitysociety.com.au/wp-content/uploads/Guidelines-for-Professional-Practice.pdf, accessed 25 October 2018.

54 For a discussion on the need to develop such counselling see: Eric Blyth, Petra Thorn and Tewes Wischmann, 'CBRC and Psychosocial Counselling: Assessing Needs and Developing an Ethical Framework for Practice' (2011) 23(5) Reproductive BioMedicine Online 642. 
Then - I don't know. On the one hand it's easier for us to say, "I'm sorry baby but in Greece they just don't allow you to contact so it's a little bit out of our hands."

Several participants appeared to have a poor understanding of the rules governing donor identity disclosure in the jurisdiction of treatment. A number of interviewees did not believe that anonymity laws would prevent them from later accessing the donor's identifying information should they or their child wish to. Cassandra, who had a young son from egg donation in Greece and was still trying for another pregnancy with the same donor, described anonymity as 'one of the downsides of doing it in another country', adding:

So if Andrew at some point wanted to better understand his genetic background, then there wouldn't be much opportunity like at this point of time. So whether the Australian Government can help facilitate some of that in the future, I don't know.

Madeline, who acknowledged that she chose an anonymous egg donor in the USA out of preference noted, similarly to Shelby, that 'on the flip side' it was a 'worry' that her son 'will probably never be able to - if he wants to find her, he'll probably never be able to', but then went on to add that she would be 'fully supportive if he wants to try and look for her.' Of some concern is the fact that three parents mentioned that they had identified, or intended to identify, their egg donor despite legal regimes which guaranteed her anonymity. Two intended parents in surrogacy arrangements, in Mexico and the USA, respectively had utilised details about the donor to identify her through Facebook, although they had not made any contact at the time of the interview. Likewise a woman who had undertaken treatment in the USA which involved donated gametes stated that she wasn't 'stuck with the decision' because 'with a bit of effort' she could probably track down the egg donor by using Google image matching, along with an adult photo of the donor and her educational history.

I suggest that the above discussion indicates that the lack of specific counselling and information about donor conception issues may be detrimental to some patients, in that they were not fully prepared for, or aware of, overseas restrictions on access to identifying information. Moreover, if patients seek to identify and contact donors in the future without their consent and without any form of professional intermediation or support, this could potentially be quite problematic. 


\section{Diagnostic work}

Three women, Carys, Beth and Rina, each of whom had no uterus, reported assistance from Australian medical specialists in assessing their potential fertility in order to pursue surrogacy overseas with their own eggs. Notably all of these doctors were approached as OB/GYNs in private practice, not as fertility specialists working within the setting of an IVF clinic.

In contrast, Alice, who also had no uterus, approached an IVF clinic because at 37 she was worried about declining fertility - and so in addition to diagnostic work she wanted to explore freezing eggs or embryos in advance of local or international surrogacy. The doctor at the IVF clinic not only refused to treat her (as was required by the law of that state) ${ }^{55}$, but also refused to undertake any fertility investigations, unless she had a domestic surrogacy agreement in place. Alice said the she felt that she was 'forced offshore' where she did a 'horrendous [IVF cycle] in India, I was over-stimulated and very ill.'

I had no idea what to compare it to either, because I'd never had IVF before. So I wasn't aware of how much of the injections I should have been having, what was safe, anything like that. ... We didn't really question anything either, we just trusted that these guys are professionals, we'd had friends that had used the same organisation and had a successful pregnancy ... So just went in trusting everything and not questioning.... I learned afterwards about how dangerous being overstimulated can be. It could have ruined all our chances for this to happen. So after the surgery... the egg pick up - I had to stay there for another 12 hours ... on a drip to try and calm the ovaries right down and then keep going back every day or every second day to have an intravenous drip with some hormone in it to try and settle everything down. I suffered a lot of pain and swelling and horrendous headaches and mood swings. Every side effect you can think of, I had. Then had to fly all the way back to Australia. But at the time, I just thought, "Oh well, this must be how some people react to it all"...It wasn't until I did the Australian round of IVF [for a subsequent domestic surrogacy arrangement] that I realized ...

Women undertaking egg donation overseas reported freely accessing the services of fertility specialists within IVF clinics for a range of diagnostic work, in addition to support from their GPs and specialist gynaecologists not associated with IVF clinics. Two USA clinics which were utilised by four participants for egg and embryo donation had exacting protocols requiring

\footnotetext{
55 The Australian states of Victoria, WA and NSW prohibit IVF treatment in pursuance of surrogacy unless an approved/assessed surrogacy arrangement has already been entered into: Assisted Reproductive Treatment Act 2008 (Vic) s 39; Human Reproductive Technology Act 1991 (WA) s 23; Assisted Reproductive Technology Act 2007 (NSW) s 15A.
} 
prospective patients to undertake a range of tests (including mammogram, chest $\mathrm{x}$-ray and sono-hystogram and a full 'uterine evaluation cycle' with the medication); all four interviewees reported the assistance of their fertility doctors as well as GPs in this process. Among those seeking egg donation abroad, three women reported that diagnostic tests requested by the overseas provider resulted in finding previously undiagnosed issues, (polyps, fibroids and a blocked fallopian tube), which were then treated by their local specialist prior to travel. Having these previously undiagnosed issues discovered and treated within Australia by their existing doctors was clearly beneficial to the on-going health of these women, regardless of the reproductive outcome.

For Carole, who undertook embryo donation in the USA, the line between diagnosis and preparatory treatment was complex to navigate:

I could get the [diagnosis and treatment] procedure done in Western Australia, but it couldn't be under the care of somebody who was helping me to get pregnant ... So I had to just go to my GP and I had to get a referral. She understood what was going on. But I had to get a referral to a gynecologist surgeon ... for... a couple of those procedures. She did the procedure and she knew what was going on, but neither of them were helping me to get pregnant and working directly with [the US clinic]. I was the one who had to get the instructions from [the US] and then go to my doctor about it. I couldn't go through ... the IVF clinic. And I had to go through the same process to organise all of my medication and my ultrasound through independent service providers that were not IVF clinics. The IVF clinics are ... not allowed to ... help me to get pregnant using donor embryos. But they - and I spoke to them directly, but they were clearly able to see me after I was pregnant and help me then, but only then.

This situation was particularly difficult for Carole as she knew another recipient, travelling from a different Australian state to utilise the same overseas provider, who was being fully assisted by her local IVF clinic.

Gay men undertaking surrogacy abroad were differently situated from most female participants in that they had not undertaken IVF, had no pre-existing relationships with Australian fertility professionals, and were not going to be a patient in the treatment abroad. A number of gay men reported that they had no contact at all with local medical professionals in advance of undertaking surrogacy overseas. Derrick said, 'I didn't seek out any medical information because it wasn't relevant I think to my situation' (surrogacy, USA). Nonetheless, 
three gay male interviewees reported that they undertook blood tests and semen analysis in Australia at the request of overseas providers, with the assistance of their GP who wrote the referrals, in order to pursue surrogacy in India, Thailand and Mexico respectively. Gabriel described his GP as 'very helpful and very nice and friendly' but lacking expertise on the 'actual nitty gritty of what's going on.' A lack of experience with Australian IVF professionals meant that male travellers were generally less well informed of the risks of multiple embryo transfer in comparison to female interviewees. For example Tom, who undertook surrogacy in India, saw nothing unusual about having four embryos transferred into the surrogate in one attempt.

\section{Preparatory Treatment}

For women undertaking surrogacy with their own eggs, if preparatory IVF treatment within Australia included egg collection (such that the eggs or embryos were then transported overseas, rather than the woman undertaking IVF treatment aboard), this would offer advantages of safety, comfort and continuity of care to the patient. Such treatment is clearly prohibited by the 2004/2007 and subsequent 2017 National Ethical Guidelines if it is part of a commercial surrogacy agreement. Two participants, Beth and Rina, reported that they did exactly this, for surrogacy in the USA and Canada respectively, with the strong support of their Australian fertility doctors. Beth was able to do so because her treatment pre-dated the 2004 introduction of the Ethical Guidelines; Rina because her clinic ethics committee and her jurisdictional regulator assessed her Canadian surrogacy arrangement as 'non-commercial.'

Beth and Rina were very much exceptions. Jody couldn't sustain a pregnancy and was trying to use her own eggs for surrogacy, but also had a diagnosed genetic issue such that she needed to undertake PGD on the embryos:

So we thought I'll do the IVF in Australia and we'll ship the embryos to India - but most of the IVF - well pretty much all of them bar one or two doctors won't have a bar of that here in Australia... Anyway, we found a doctor that said I will help you - a doctor that we'd used prior and she said "but I won't entertain any country but America. I'll help you ship the embryos over there."

Other women who sought much lower levels of assistance from fertility doctors, primarily monitoring and medication in advance of egg retrieval to be undertaken overseas for 
surrogacy, received short shrift. Jane had already undertaken one unsuccessful surrogacy attempt in India with her own eggs when she approached an Australian fertility specialist in an IVF clinic to assist her with the preparatory treatment for a second attempt:

So I went in and had an appointment with this lady and I talked to her about, could I start the process off here. Because I'd already done it once in India, but I didn't want to go back for the full three weeks and leave my family. She was absolutely horrified... She was supposed to be a pro surrogacy IVF doctor, and she said she had helped people with surrogacy before through America. But when it came to India, she was very against it.... I was so horrified by what she'd said and so shocked.

Interestingly the above quotes from Jody and Jane suggest that some fertility specialists working within IVF clinics were prepared to breach prohibitions on facilitating commercial surrogacy when undertaken in the USA, regarding it as a safer and more ethical destination than India. ${ }^{56}$ However for most clinicians, the refusal was a blanket one. Imogen was attempting surrogacy in the USA with her own eggs and had received her preparatory medications directly from the overseas doctor, but still needed a local Australian doctor to monitor her response to the medication in advance of the travel. Such monitoring is important to plan the pregnancy attempt but also to prevent complications and adverse events such as ovarian hyperstimulation.

That was really awkward, and really weird, because ... I managed to get an appointment with [a doctor at an IVF clinic] and she basically said to me, "look, don't tell anybody that I'm doing this for you. We're not allowed to do it, and I don't - don't tell anybody. We're not allowed to do it. I don't like what you're doing. But you're here now, so let's have a look." She was not impressed with the whole surrogacy... we didn't talk a lot about it because I was there for 10 minutes. ... I didn't go back to her because I thought: that's completely crazy. $\cdots$

I literally went walking down [a suburban main street] going, "I'm sure there's got to be somebody here with an ultrasound wand who could do this." ... All I needed was somebody to be able to give me a film of what all the follicles looked like so that I could scan it and send it. ... I went to [an out of hours' medical clinic].... They don't care who you are. They just do whatever. So I said to the guy, "look, I desperately need an ultrasound, blah, blah, blah"... then he said, "well, you can try these three [ultrasound services]", and ... [one] took [the referral] and he did it, and it was done.

\footnotetext{
56 One exception was a male interviewee who reported that his male partner was assisted by an IVF clinic to retrieve, test, store and then transport his semen to Mexico for use in a commercial surrogacy arrangement (so that he did not have to travel at all to undertake the arrangement).
} 
Carys, who was undertaking surrogacy with her own eggs in the USA, had a GP who assisted the process. The GP wrote referrals for ultrasounds and prescriptions under the direction of the overseas doctor, to prepare Carys for egg retrieval in the USA, and then again with follow up scans and blood tests afterwards, directed by, and sent to, the overseas doctor. Carys reported that it was she who communicated all of this information back and forth, to the extent that the ultrasound practice put all of the scans on a USB so that she could send them directly to her US doctor.

Among the egg donation cohort, local medical assistance was much easier to come by, both from GPs and from doctors within IVF clinics. Therese, Katinka and Cassandra all characterised their need for preparatory treatment as simply 'getting' their Australian doctor to write scripts or referrals. In Katinka's words:

I just rocked into a GP and said, this is what I'm doing and this is what I need. I want you to write me a script for $X, Y$ and $Z$ and give me a form for this ultrasound. The GP did that without any issue at all - whereas ... some fertility specialists ... they perceive it as them helping us break the law if they actually enable that...

Rosalind and Cassandra undertook egg donation in Greece, Therese in Spain, Madeline and Tasha did so in the USA, Helen in South Africa and Nerida undertook embryo donation in the USA and egg donation in South Africa in different attempts. All seven reported that their Australian fertility doctor and IVF clinic assisted them with 'before care' including the provision of medication, monitoring through ultrasound scans and blood tests, and then follow up with pregnancy tests and monitoring, such as the seven week foetal heartbeat scan, upon return. Interviewees reported this assistance as supporting them in a process which they were 'driving'. As discussed below this contributed to continuity of care, but did not always guarantee it.

\section{Follow up Treatment}

Three participants reported early miscarriages following egg donation abroad. This was a difficult and isolating experience in which the absence of local follow-up care was acutely felt. Leah stated of her experience after returning from Greece, 'there was no follow up, there was no ultrasound, there was no nothing. So we actually don't know what happened.' Leah changed to a different IVF clinic in Greece following her experience and characterised herself 
as 'cutting out the middle man' when she stopped seeing her Australian IVF doctor. However, Leah was in need of further medical care as her periods stopped altogether following the cycle in which she miscarried. She stated that her new Greek fertility doctor, whom she had only consulted with via Skype, was treating her for this complication:

He tells me what I need. He writes it down for me. I take it to my GP who's fully aware of my journey ... so I just have to make sure that he's written down for me the correct spelling of the medication that I need, what it's for. Then I just tell him a little bit about the background as to why we're doing it and then he'll write me an Australian script for it, so that's how we're coordinating it at the moment. Yeah, he's supporting me through it because I think he understands what a terrible tough time I went through last time.

Conversely, Therese who was pregnant upon return to Australia from Spain, did not return the follow up phone calls from her Spanish clinic:

I just hid for them because I thought if I miscarry in two weeks' time, I really didn't want them to be able to use my data as a positive pregnancy test. Then I did finally get back to them and say, "We've had a 10-week scan [through her Australian IVF clinic], and looking good." They haven't been in touch since, so tick box, job done.

While several of the egg donation cohort reported follow up care from their Australian IVF provider upon return, there were gaps in cover. After overseas treatment, Olivia's Australian fertility doctor undertook follow up blood tests and a foetal heartbeat scan but she was unsure about who to turn to at that juncture:

... it's quite confusing when you get back because you've never kind of got the continuity of care which is quite hard. So I'm still in contact with the nurse coordinator in the US and emailing her to tell her what's happening.

The real danger that lack of continuity of care poses to patient safety is exemplified by Madeline's experience. Madeline undertook egg donation in the USA and returned home to Australia; her ectopic pregnancy was only diagnosed because she sought further investigation from her GP after blood results showed that her hormones were not rising as they should have with a positive pregnancy result:

I was a little bit disappointed with the care I received from both [the US] and the doctor here because there seemed to be a bit of - to us there seemed to be a bit of a battle between who was right. The [fertility] doctor here wouldn't do an ultrasound on me because it was ... less than six weeks, so it would have been very difficult to see anything. However ... I just wanted to make sure that, well I just wanted to identify where exactly the embryo was. I was clearly pregnant but I wasn't - there was a problem. So I didn't want to end up a situation where I would be in emergency 
and have some doctor perform surgery on me and run the risk of never being able to carry a child. I know that sounds quite dramatic but I wanted it to be on my terms. So I went to my GP who sent me straight away for an ultrasound at which time they confirmed that there was nothing in the uterus but they could see a mass in one of my tubes. So she then referred me to a [different] gynecologist and he did the surgery the following day.

In sum, patient reports demonstrate a fragmented and bewildering medical landscape in Australia, in which their ability to access care and expertise varied markedly depending upon the kind of treatment they were seeking abroad, their state of residence, and the mode of practice of the Australian doctor. It is important to recollect that overseas surrogacy and egg donation breach Australian laws and ethical principles for exactly the same reasons: because they involve payment to contributors and (frequently but not always) the use of unidentifiable gamete providers. Yet those seeking egg donation were offered information and received a wide range of diagnostic and preparatory treatments in many but not all Australian states, while those seeking surrogacy were shunned, chided and offered limited (and sometimes covert) assistance.

This strikingly differential response both as between the kinds of treatment sought abroad, and in the sites of local assistance-with specialists outside IVF clinics considerably more willing to engage than those within them-is almost certainly an outcome of wording of the 2004/7 National Ethical Guidelines. As noted those Guidelines contained broader and vaguer prohibitions on IVF clinics engaging with commercial surrogacy compared to egg donation, and do not apply to practitioners outside of IVF clinics. It thus appears that the Guidelines, while trying to promote ethical practice in assisted reproduction in Australia, generated a perverse outcome for Australians engaged in $\mathrm{CBRC}$ in that they actively drove patients away from specialist local expertise. This reduced the ability of some patients to engage in informed decision-making in dialogue with their local doctor and also reduced patients' ability to access diagnostic or preparatory treatment within Australia. In turn this meant prolonging their treatment abroad and potentially increased their exposure to less safe treatment practices such as hyperstimulation. GPs were notably more willing to assist but this was usually limited to following the directions of an overseas practitioner to generate scripts and tests, rather than offering specialist input on risks. 
Even when some form of domestic treatment was available, and in instances where it was undertaken under the direction of the overseas practitioner such that it arguably came within the notion of collaborative care raised in the introduction, such care was fragmented. Only a handful of participants reported that their local medical records were provided to overseas practitioners. Notably, most patients reported that treatment instructions were not communicated directly between their doctor abroad and their Australian doctor, but were rather transmitted through themselves. The patient herself often took emailed instructions from the overseas doctor to a local consultation, or physically collected test results and emailed them directly back to the overseas doctor. These practices highlight a series of 'Chinese walls' through which local practitioners appear to be seeking to protect themselves from allegations of impropriety whilst continuing to provide some form of on-going care for their patients.

Is there scope in Australia for developing continuity of care as a harm reduction strategy in CBRC?

In 2017 substantially revised National Ethical Guidelines on assisted reproductive treatment were released. For the first time, the Guidelines include a number of specific provisions on CBRC. The amorphous language of 'facilitation' was removed from the provision on commercial surrogacy which was clarified as follows:

8.8.1 Clinics and clinicians must not practise, promote or recommend commercial surrogacy, nor enter into contractual arrangements with commercial surrogacy providers. (emphasis added)

Recollecting that the Guidelines prohibit trading in gametes as well as anonymous gamete donation, they also provide:

4.2.7 Clinics and clinicians must not promote or recommend practices which contravene these Ethical Guidelines or Australian legislation, nor enter into contractual arrangements with overseas providers who offer such practices. (emphasis added)

It would appear from these provisions that both direct referral and general information giving about surrogacy and egg donation (such as the commonly reported practice of 'suggesting' a country for donor eggs noted above) are now prohibited alike. 
The new provisions for the first time include clear guidance on information giving about treatment risks and standards.

4.2.8 Clinics approached by an individual or a couple for advice on undertaking ART overseas have an ethical obligation to advise the individual or couple of any concerns about the standard of care in the overseas clinic or acknowledge where the standard of care is unknown.

4.2.9 Where an individual or couple has made an autonomous decision to seek ART overseas, clinics may provide information aimed at the reduction of harm to the intended parent(s) and the person who would be born. This may include advice aimed at reducing the likelihood of ovarian hyperstimulation, the promotion of single embryo transfer and supporting the right of persons born from donated gametes or embryos to know the details of their genetic origins. (emphasis added)

These provisions are broadly in accord with the first recommendation in the RANZCOG Position Statement on CBRC, and represent a significant improvement in that they explicitly state that a clinician can contribute to their patient's informed decision-making in CBRC without falling into ethical breach. This is particularly important, given the findings of researchers in Australia, and comparable jurisdictions such as the UK, that CBRC patients increasingly inform (and misinform) themselves through online peer forums and may miss out on crucial advice from specialist doctors. ${ }^{57}$

However, the vexed question of the extent to which an IVF doctor may participate in care of their patient undertaking CBRC (in circumstances where there is no contractual arrangement between providers), ie through the collaborative provision of diagnostic or preparatory treatment, remains unsettled. The Guidelines state:

4.2.10 Where an individual or couple has made an autonomous decision to seek ART overseas, a clinician may feel they have an ethical obligation to participate in elements of the treatment of the individual or couple in order to minimise potential harms, however:

- clinicians have no obligation to participate in such treatment ...

- clinicians should be aware of the relevant legislation in the relevant state or territory before participating in the treatment in such circumstances. (emphasis added)

\footnotetext{
57 Stuhmcke et al forthcoming; Hammarberg et al, above n 51, 692; Rodino et al, above n 23, 1429; Jackson et al, above n 27; Lorraine Culley et al, "“What Are You Going to Do, Confiscate Their Passports?” Professional Perspectives on Cross-Border Reproductive Travel' (2013) 31(1) Journal of Reproductive and Infant Psychology 46.
} 
As with the RANZCOG recommendation on CBRC, the National Guidelines throw the onus back upon the practitioner to 'be aware' of Australian legal restrictions. Recollecting as discussed above that these laws are a complex matrix of provisions, with extraterritorial prohibitions concerning commercial surrogacy in three states and territories, this final dot point arguably sends fertility health professionals straight back into confusion as it does not spell out which 'elements' of treatment are permissible. This provision also highlights that in the piecemeal Australian system, reform of any one aspect, such as the Guidelines, is manifestly insufficient if undertaken alone.

\section{Conclusion}

Patient-centred care requires a context in which a medical practitioner is able to put the health needs of their patient first if she is contemplating or undertaking treatment abroad, even - perhaps especially - if such treatment is unlikely to meet Australian clinical and ethical standards. To date Australian regulation has arguably hindered rather than helped the objective of securing safer outcomes for Australians undertaking CBRC.

The findings reported here from the experiences of 37 individuals and couples who undertook surrogacy and egg and embryo donation abroad demonstrate that the input of Australian healthcare professionals into their CBRC treatment was inconsistent, inadequate and highly fragmented. The involvement of Australian practitioners generally comprised a limited technical or clinical aspect of the overall 'assemblage' of medical services accessed by travelling patients. Patients rarely saw themselves as continuing under the care of their local practitioner, and even more rarely viewed that professional as a source of on-going advice or counsel.

Even when domestic practitioners did retain some involvement with their patient for diagnostic or preparatory treatment it appeared that practitioners and patients tip-toed around fine legal lines. As a result, continuity of care was compromised because medical practitioners were not communicating directly. Information giving and counselling, which 
could have assisted in informed decision-making concerning both clinical and ethical aspects of treatment abroad, was largely unavailable.

Complications and adverse or potentially negative outcomes reported by participants included: multiple birth rates considerably higher than those occurring in Australia; ovarian hyper stimulation among participants (and at least one egg donor); amenorrhea; miscarriages with no follow up care; and common use of unidentifiable donors accompanied by a degree of both ambivalence and confusion among a number of parents concerning the consequences of anonymity.

This paper argues that an ethical approach to Australian involvement CBRC must take a patient-centred approach in order to advance harm minimisation through enhanced opportunities for informed consent and continuity of care. This requires a clear and consistent legal and ethical framework; one in which health professionals (and their patients) are able to understand and comply with their obligations. Such an approach will require substantial change and harmonisation of existing legal and ethical regulation within Australia so that obligations are consistent across place of residence of the patient, the kind of treatment sought and the site and the mode of practice of the professional. 